Review article

\title{
The influence of interunit carbon-carbon linkages during lignin upgrading
}

\author{
Li Shuai, Masoud Talebi Amiri, Jeremy S. Luterbacher* \\ Laboratory of Sustainable and Catalytic Processing, Institute of Chemical Sciences and Engineering, École Polytechnique Fédérale de Lausanne (EPFL), CH-
} 1015, Lausanne, Switzerland

\section{A R T I C L E I N F O}

Article history:

Received 15 July 2016

Received in revised form

4 October 2016

Accepted 14 October 2016

Available online 18 October 2016

\begin{abstract}
A B S T R A C T
The cleavage of $\beta-0-4$ linkages in lignin can generate monomers with a phenyl propane structure that can easily be upgraded into valuable hydrocarbon biofuels and renewable aromatic chemicals. High-yield lignin monomer production from extracted (or technical) lignin that is produced in a practical way could facilitate the productivity and profitability of biomass conversion processes. However, interunit carbon -carbon $(\mathrm{C}-\mathrm{C})$ linkages present in native lignin or formed during lignin condensation in biomass pretreatments dramatically reduce lignin monomer yields. Here, we present a perspective on biological and chemical strategies that have been successfully used to reduce the formation of $\mathrm{C}-\mathrm{C}$ linkages in native or technical lignin. We analyze the mechanisms involved in these strategies and offer our views on improving the quality of technical lignin resulting from biomass conversion in order to achieve highyield lignin monomer production.
\end{abstract}

() 2016 Published by Elsevier B.V.

\section{Introduction}

Lignin is the second most abundant natural polymer on earth after cellulose, accounting for $15-30 \mathrm{wt} \%$ of lignocellulosic biomass [1]. Million tons of lignin are produced annually during biomass fractionation, and treated as waste and/or burned for heat in pulp mills or biorefineries. To valorize lignin, catalytic hydrogenolysis has been widely investigated to break lignin into monomers that can be further upgraded to fuels and chemicals [2]. However, the resulting monomer yields are significantly influenced by the number of interunit $\mathrm{C}-\mathrm{C}$ linkages in native lignin, and by additional interunit $\mathrm{C}-\mathrm{C}$ linkages formed during lignin extraction (in a process called biomass pretreatment or biomass fractionation) [3,4]. Here, we discuss the formation of $\mathrm{C}-\mathrm{C}$ linkages in native lignin and extracted or "technical" lignin (we use the term technical lignin below to refer to this extracted lignin) and analyze possible strategies for decreasing their formation to facilitate the high yield production of monomers.

\footnotetext{
* Corresponding author.

E-mail address: jeremy.luterbacher@epfl.ch (J.S. Luterbacher).
}

\section{2. $\mathrm{C}-\mathrm{C}$ linkage formation in native lignin}

Lignin is formed by three natural monolignol monomers with a phenyl propane backbone: p-coumaryl alcohol, coniferyl alcohol, and sinapyl alcohol. These monomers are incorporated into lignin as several phenylpropanoid moieties that include $p$-hydroxyphenyl $(\mathrm{H})$, guaiacyl (G), and syringyl (S) units (Fig. 1A) [5]. Polymerization of these monolignols occurs by oxidative radicalization of phenolic hydroxyl groups followed by radical coupling [6]. The phenolic radical that is formed is stabilized through delocalization of the unpaired electron at the 1,5 and/or $\beta$ positions, depending on the substitution groups on the aromatic ring (Fig. 1B) [5]. These radicals can couple to form different linkages. Phenolic radicals couple with the $\beta$ and 5 positions to form $\mathrm{C}-\mathrm{O}$ bonds including $4-\mathrm{O}-5$ linkage and $\beta-\mathrm{O}-4$ linkage, respectively (Fig. $1 \mathrm{C}$ ). Radicals at the positions of 1,5 and $\beta$ couple with the radicals at the 5 and $\beta$ positions to form $C-C$ linkages including $5-5, \beta-5, \beta-1$ and $\beta-\beta$ (Fig. 1D) [5]. In a typical native lignin polymer, about $1 / 4$ to $1 / 2$ of interunit linkages are robust $\mathrm{C}-\mathrm{C}$ linkages (Table 1 ), which limit the theoretical yield of lignin monomers from wood to around 40-55\% (based on the mass of native lignin). Sinapyl alcohol cannot participate in the formation of any linkages associated with a 5 position, since this is occupied by a methoxy group. Analysis of lignin has shown that softwood has a lower content of syringyl units compared to 


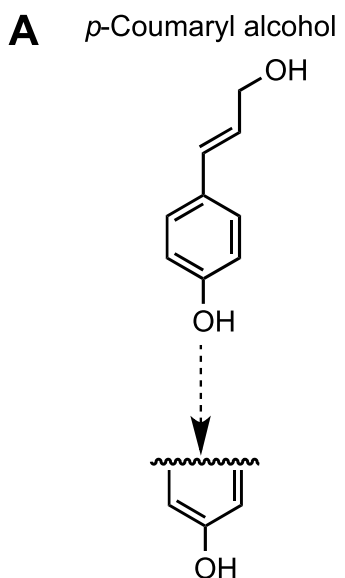

p-Hydroxyphenyl $(\mathrm{H})$

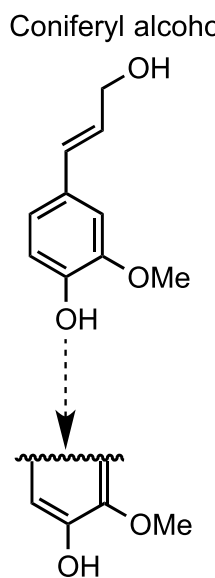

Guaiacyl (G)<smiles>COc1cc(/C=C/CO)cc(OC)c1O</smiles>

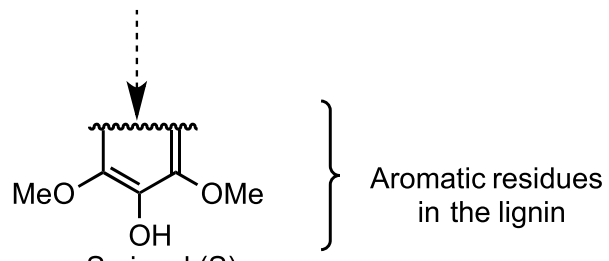

B<smiles>COC(=O)/C=C/c1cc(/C=C/CO)ccc1OC</smiles>

C<smiles>COc1cc(C(C)(C)C)cc(C)c1OC(CO)C(O)c1cc(C)c(OC(C)(C)C)c(OC)c1</smiles><smiles>COc1cc(C(C)(C)C)ccc1Oc1cc(C(C)(C)C)cc(OC)c1O</smiles>

4-0-5'<smiles>COc1cc(C2Oc3c(OC)cc(C(C)C)cc3-c3cc(C(C)C)cc(OC)c3OC2CO)cc(C)c1OC(C)(C)C</smiles><smiles>COc1cc(C2Oc3c(OC)cc(C(C)C)cc3C2CO)cc(C)c1OC(C)C</smiles>

Phenylcoumaran ( $\beta-5 \%$ / $\left.\alpha-0-4^{\prime}\right)$ 
Table 1

Fraction of total linkages present in softwood and hardwood lignins. ${ }^{a}$

\begin{tabular}{llll}
\hline Linkage type & Dimer structure & \multicolumn{2}{l}{$\begin{array}{l}\text { Fraction of total linkages } \\
(\%)\end{array}$} \\
\cline { 3 - 4 } & & Softwood & Hardwood \\
\hline$\beta-\mathrm{O}-4^{\prime}$ & Phenylpropane $\beta$-aryl ether & $45-50$ & 60 \\
$5-5^{\prime}$ & Dibenzodioxocin & $25-30$ & $5-10$ \\
$\beta-5^{\prime}$ & Phenylcoumaran & $9-12$ & 6 \\
$\beta-1^{\prime}$ & Spirodienone & $1-2$ & $1-2$ \\
$4-\mathrm{O}-5^{\prime}$ & Diaryl ether & $<4$ & $<6.5$ \\
$\beta-\beta^{\prime}$ & $\beta-\beta$-linked structure & $2-6$ & $3-12$ \\
$\alpha-\mathrm{O}-4^{\prime}$ & Phenylpropane $\alpha$-aryl ether & A few & A few \\
\hline Note. & & \\
a Table was adapted from Ref. [8]. & &
\end{tabular}

form intra-(Fig. 2A) or inter- (Fig. 2C) unit C-C linkages. In acidic conditions, the condensation mechanism involves the formation of a benzylic carbocation at the $\alpha$ position followed by a reaction of this moiety with an electron-rich aromatic ring to form a $\mathrm{C}-\mathrm{C}$ linkage (Fig. 2C). Mechanistic studies of the acidolysis of models for the $\beta-0-4$ linkage have found that self-condensation is thermodynamically favorable and occurs spontaneously after the formation of the benzylic carbocation (see the corresponding energy diagram for model compound acidolysis in Fig. 2B) [12]. This suggests that lignin condensation occurs faster than or as fast as lignin depolymerization. This favorable condensation pathway is likely to be a major reason why technical lignin has generally undergone significant condensation after isolation $[3,4,12]$.

\section{Strategies to decrease $\mathrm{C}-\mathrm{C}$ formation}

Pyrolysis and gasification can break $\mathrm{C}-\mathrm{C}$ linkages with high reaction temperatures [2,13-15], but these are high-temperature thermochemical conversion processes that lead to low selectivity for any products besides full gasification products and/or heavy char formation. Compared to these unselective thermochemical conversion strategies, catalytic hydrogenolysis is milder and more selective, but cannot break $\mathrm{C}-\mathrm{C}$ linkages. Therefore, we argue that decreasing $\mathrm{C}-\mathrm{C}$ linkages in both native and technical lignin for selective upgrading is crucial to its eventual valorization.

\subsection{Biological strategies}

Genetic modification of plants to decrease interunit $\mathrm{C}-\mathrm{C}$ linkages has been explored as a strategy to improve upgrading possibilities [16,17]. Recently, Franke et al. over-expressed the Arabidopsis gene encoding ferulate 5-hydroxylase that catalyzes the formation of syringyl lignin units, and generated a transgenic poplar with $97.5 \%$ syringyl units. The increased syringyl unit content significantly reduced the formation of interunit $\mathrm{C}-\mathrm{C}$ linkages associated with the 5 position [18]. Ralph and co-workers incorporated epigallocatechin gallate (EGCG) [19] and hydroxycinnamate units [20] into lignin to form novel interunit ester linkages that were easily disrupted at mild temperatures (e.g. $100{ }^{\circ} \mathrm{C}$ ) during dilute acid or alkali pretreatments. Although the incorporation may not directly decrease $\mathrm{C}-\mathrm{C}$ linkages in native lignin, mild pretreatment conditions applied during fractionation may reduce the subsequent formation of $\mathrm{C}-\mathrm{C}$ linkages.

\subsection{Chemical strategies}

Several studies have focused on improving chemical or catalytic biomass fractionation. However, tuning catalysts has had little effect on improving monomer yields because lignin's robust $\mathrm{C}-\mathrm{C}$ linkages could not be cleaved by catalytic hydrogenolysis. Instead, catalytic reductive pulping has been recently developed. This method mixes biomass particles with solid catalysts under an acidfree environment, leading to near theoretical yields (45-55\%) of monomers [7,21]. However, mixing and subsequently separating these two solids may have several technical limitations at industrial scales, including those associated with mass transfer, catalyst recovery or catalyst deactivation. In parallel, the catalytic oxidation of lignin has been extensively investigated to break $\mathrm{C}-\mathrm{O}$ and $\mathrm{C}-\mathrm{C}$ linkages but most of these processes were non-selective and led to high carbon loss [22]. Recent work has shown that selective oxidation of $\alpha$ hydroxyl group could weaken $\beta-0-4$ linkages [23-25], which could subsequently be cleaved by formic acid to generate monomer at yields above $60 \mathrm{wt} \%$ [25]. However, the efficacy of this method depended on the availability of $\alpha$ hydroxyl groups that are only present in abundance in uncondensed native lignin. Therefore, Rahimi et al. used an $\alpha$ hydroxyl-rich cellulolytic lignin that was produced by repeated ball milling and enzymatic treatments-a method that is not industrially viable [25].

We contend that more practical methods are needed to decrease lignin condensation during its extraction. Such methods should involve pretreatment, in order to be compatible with biomass polysaccharide upgrading. Since both temperature and acid loading affect the rate of condensation, using mild conditions during pretreatment can contribute to limiting lignin condensation. High yields of technical lignin were obtained using GVL as a solvent with low acid loadings $\left(<2 \mathrm{wt} \% \mathrm{H}_{2} \mathrm{SO}_{4}\right)$ at low temperatures $\left(120{ }^{\circ} \mathrm{C}\right.$ ) $[26,27]$. The lignin led to reasonable lignin monomer yields after hydrogenolysis (>30 mol\% for corn stover and near $20 \mathrm{~mol} \%$ for maple wood) [26,27]. NMR analyses showed that the native lignin structure was partially preserved in GVL-extracted corn stover lignin, including the dominant $\beta-0-4$ linkages.

Lignin produced during ethanol organosolv biomass pretreatment has been widely used as a feedstock for generating lignin monomers. Compared to dilute acid pretreatment, technical lignin produced with ethanol organosolv pretreatment led to decent yields of monomers during subsequent hydrogenolysis (1-8\%) $[4,28]$. Ethanol can function as a reactive stabilization reagent, which plays an important role in decreasing lignin condensation. Specifically, ethanol, catalyzed by the acidic conditions, can react with benzylic carbocation to form an ethoxy group (Fig. 3). The ethoxy group protects the benzylic carbocation position, and decreases the probability of interunit $\mathrm{C}-\mathrm{C}$ linkage formation [29]. The stabilization efficacy is dependent on the nucleophilicity of the stabilization reagent. An ideal stabilization reagent should readily react with side chains and/or aromatic rings to protect them prior to condensation.

\section{Conclusion}

Genetic engineering of native lignin has been successful in controlling the amount of lignin in plants and the fraction of interunit $\mathrm{C}-\mathrm{C}$ linkages in native lignin, and in introducing new types of bonds within the lignin polymer. In parallel, decreasing lignin condensation during biomass fractionation is a viable and compatible strategy to separate high-quality lignin for selective upgrading. Mild lignin extraction and stabilization has shown to improve the quality of extracted lignin, and the resulting monomer yields after hydrogenolysis. Although both chemical and biological strategies for improving lignin yields and reducing condensation can be explored independently, we believe that ultimately, a combined approach targeting both native and extracted lignin will be the most successful in facilitating practical lignin upgrading processes. 
A

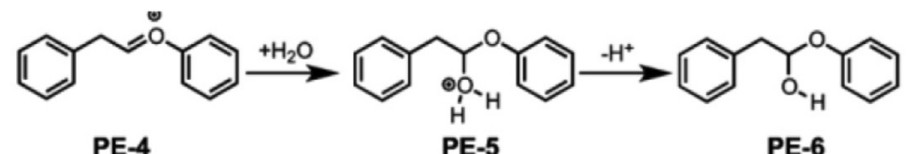

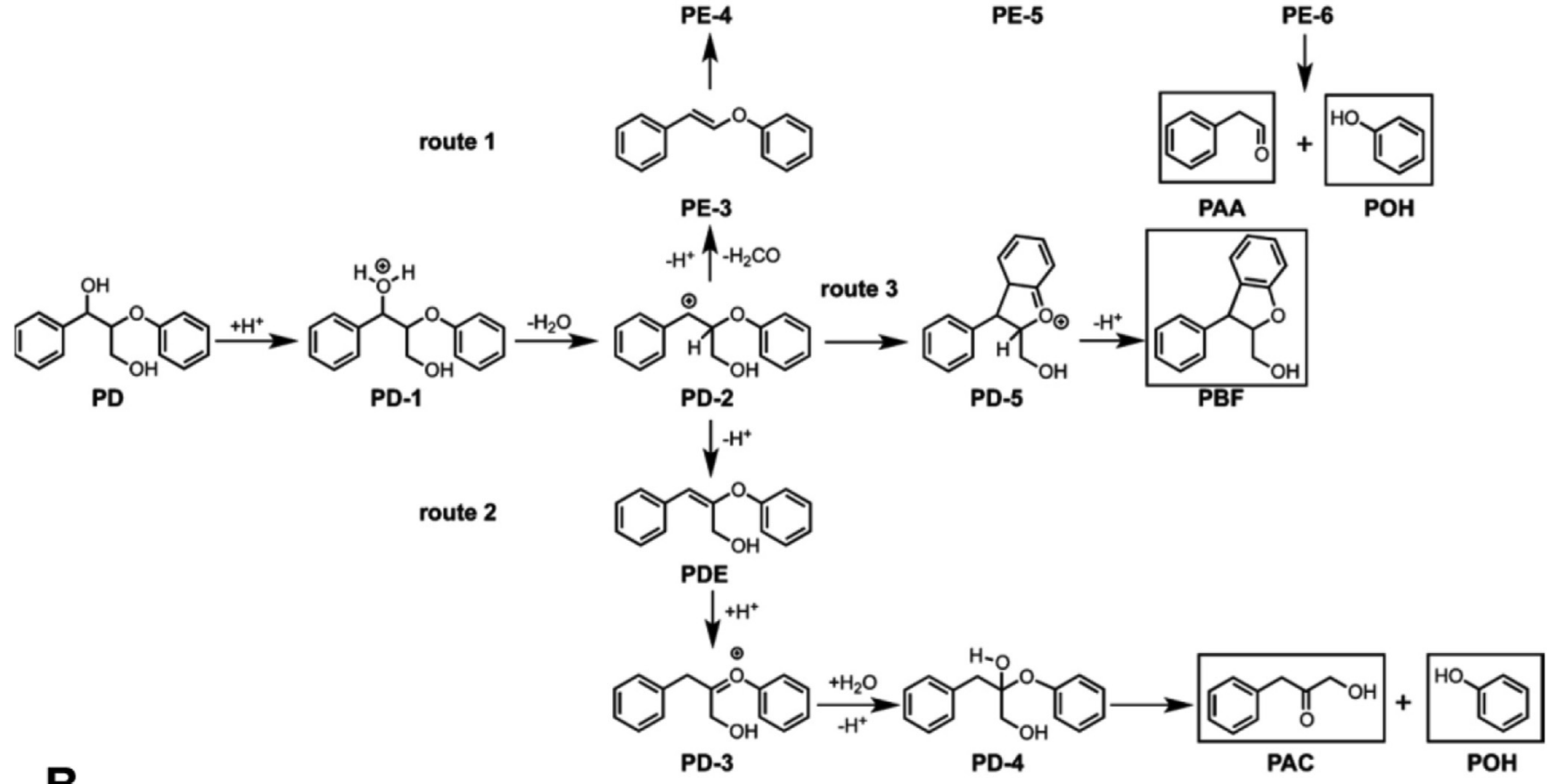

B

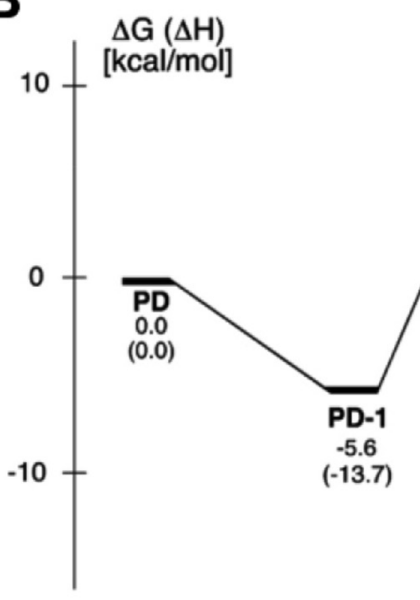

PD-3

PD-4

POH

reaction coordinate
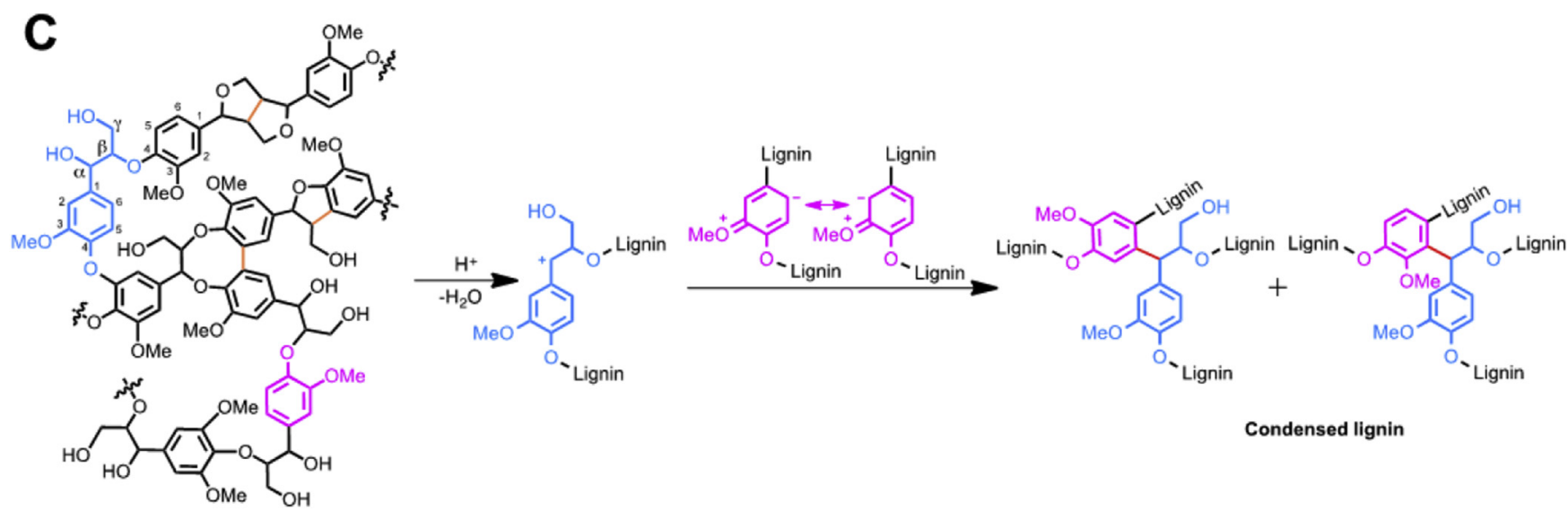

Fig. 2. Mechanism of lignin acidolysis. (A) Acidolysis routes for a lignin model compound representing the $\beta-0-4$ linkage, (B) reaction energy diagrams of the different routes for a lignin model compound representing the $\beta-0-4$ linkage, and $(C)$ interunit condensation of lignin in an acidic environment. Parts $A$ and $B$ are reprinted with permission from Ref. [12]. Copyright (2014) American Chemical Society. 

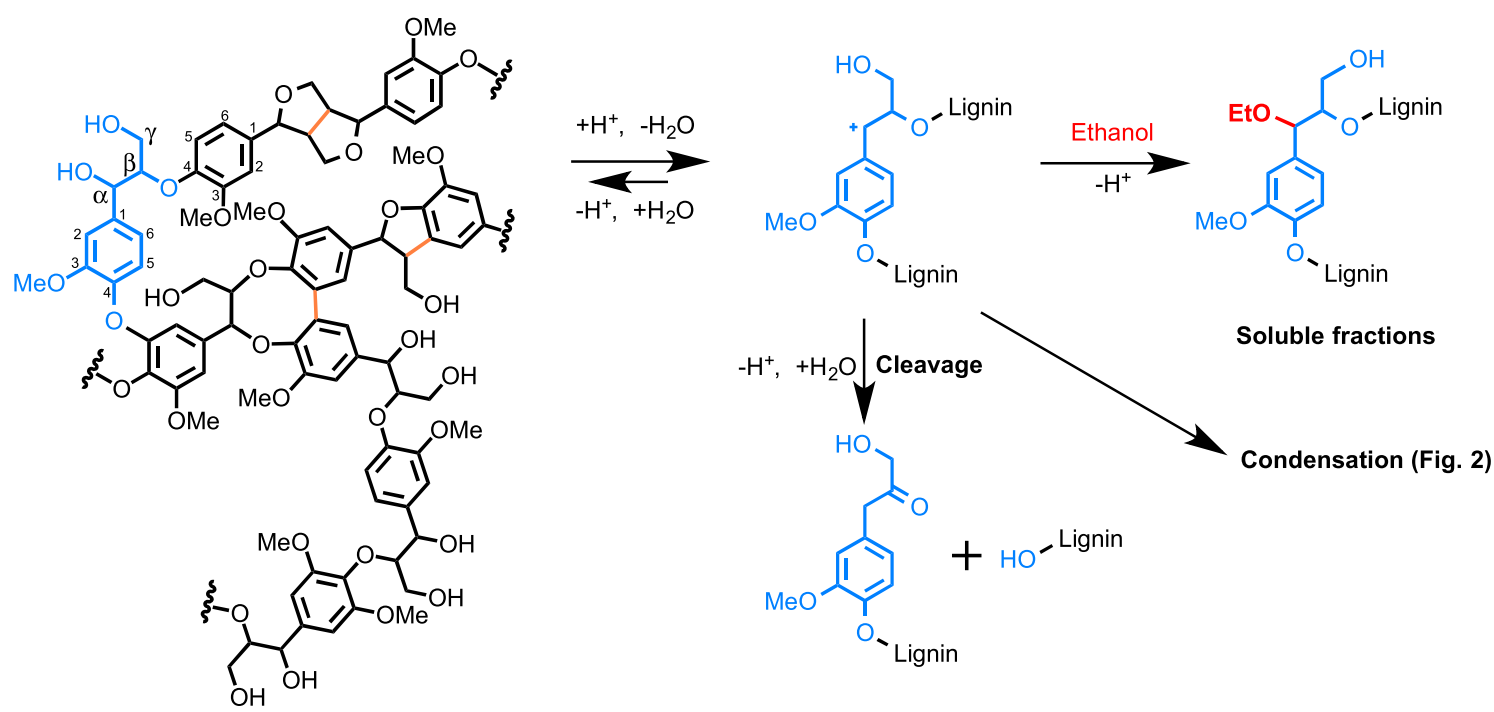

Fig. 3. Mechanism of reduced lignin condensation in a traditional ethanol organosolv pretreatment process.

\section{Acknowledgements}

The authors acknowledge funding from the Swiss Competence Center for Energy Research: Biomass for a Swiss Energy Future through the Swiss Commission for Technology and Innovation grant KTI.2014.0116; from the Swiss National Science Foundation through grant PYAPP2_154281; and from EPFL.

\section{References}

[1] J. Zakzeski, P.C.A. Bruijnincx, A.L. Jongerius, B.M. Weckhuysen, The catalytic valorization of lignin for the production of renewable chemicals, Chem. Rev. 110 (2010) 3552-3599.

[2] A.J. Ragauskas, G.T. Beckham, M.J. Biddy, R. Chandra, F. Chen, M.F. Davis, B.H. Davison, R.A. Dixon, P. Gilna, M. Keller, P. Langan, A.K. Naskar, J.N. Saddler, T.J. Tschaplinski, G.A. Tuskan, C.E. Wyman, Lignin valorization: improving lignin processing in the biorefinery, Science 344 (2014) 1246843.

[3] C. Xu, R.A.D. Arancon, J. Labidi, R. Luque, Lignin depolymerisation strategies: towards valuable chemicals and fuels, Chem. Soc. Rev. 43 (2014) 7485-7500.

[4] H. Wang, M. Tucker, Y. Ji, Recent development in chemical depolymerization of lignin: a review, J. Appl. Chem. (2013). Article ID 838645, 9 pages, (2013).

[5] J. Ralph, K. Lundquist, G. Brunow, F. Lu, H. Kim, P.F. Schatz, J.M. Marita, R.D. Hatfield, S.A. Ralph, J.H. Christensen, W. Boerjan, Lignins: natural polymers from oxidative coupling of 4-hydroxyphenyl- propanoids, Phytochem. Rev. 3 (2004) 29-60.

[6] R. Vanholme, B. Demedts, K. Morreel, J. Ralph, W. Boerjan, Lignin biosynthesis and structure, Plant Physiol. 153 (2010) 895-905.

[7] S.V. den Bosch, W. Schutyser, R. Vanholme, T. Driessen, S.F. Koelewijn, T. Renders, B.D. Meester, W.J.J. Huijgen, W. Dehaen, C.M. Courtin, B. Lagrain, W. Boerjan, B.F. Sels, Reductive lignocellulose fractionation into soluble ligninderived phenolic monomers and dimers and processable carbohydrate pulps, Energy Environ. Sci. 8 (2015) 1748-1763.

[8] L. Shuai, Transforming Lignocelluloses to Sugars and Liquid Fuels, University of Wisconsin-Madison, 2012.

[9] L. Shuai, Q. Yang, J.Y. Zhu, F.C. Lu, P.J. Weimer, J. Ralph, X.J. Pan, Comparative study of SPORL and dilute-acid pretreatments of spruce for cellulosic ethanol production, Bioresour. Technol. 101 (2010) 3106-3114

[10] H.L. Trajano, N.L Engle, M. Foston, A.J. Ragauskas, TJ. Tschaplinski, C.E. Wyman, The fate of lignin during hydrothermal pretreatment, Biotechnol. Biofuels 6 (2013) 110.

[11] T. Yokoyama, Revisiting the mechanism of $\beta-0-4$ bond cleavage during acidolysis of lignin. Part 6: a review, J. Wood Chem. Technol. 35 (2014) 27-42.

[12] M.R. Sturgeon, S. Kim, K. Lawrence, R.S. Paton, S.C. Chmely, M. Nimlos, T.D. Foust, G.T. Beckham, A mechanistic investigation of acid-catalyzed cleavage of aryl-Ether linkages: implications for lignin depolymerization in acidic environments, ACS Sustain. Chem. Eng. 2 (2014) 472-485. This article presented an experimental and theorectical study of the acid-catalyzed cleavage of $\beta-0-4$ linkages in various model compounds, clarified its mechanism and explained the disparity between rates of $\mathrm{B}-\mathrm{O}-4$ cleavage for model compounds and real biomass.
[13] M.P. Pandey, C.S. Kim, Lignin depolymerization and conversion: a review of thermochemical methods, Chem. Eng. Technol. 34 (2011) 29-41.

[14] W.-J. Liu, H. Jiang, H.-Q. Yu, Thermochemical conversion of lignin to functional materials: a review and future directions, Green Chem. 17 (2015) 4888-4907.

[15] D. Shen, G. Liu, J. Zhao, J. Xue, S. Guan, R. Xiao, Thermo-chemical conversion of lignin to aromatic compounds: effect of lignin source and reaction temperature, J. Anal. Appl. Pyrolysis 112 (2015) 56-65.

[16] M. Baucher, C. Halpin, M. Petit-Conil, W. Boerjan, Lignin: genetic engineering and impact on pulping, Crit. Rev. Biochem. Mol. Biol. 38 (2003) 305-350.

[17] A.M. Anterola, N.G. Lewis, Trends in lignin modification: a comprehensive analysis of the effects of genetic manipulations/mutations on lignification and vascular integrity, Phytochemistry 61 (2002) 221-294.

[18] R. Franke, C.M. McMichael, K. Meyer, A.M. Shirley, J.C. Cusumano, C. Chapple, Modified lignin in tobacco and poplar plants over-expressing the Arabidopsis gene encoding ferulate 5-hydroxylase, Plant J. 22 (2000) 223-234.

[19] S. Elumalai, Y. Tobimatsu, J.H. Grabber, X. Pan, J. Ralph, Epigallocatechin gallate incorporation into lignin enhances the alkaline delignification and enzymatic saccharification of cell walls, Biotechnol. Biofuels 5 (2012) 59.

[20] Y. Tobimatsu, S. Elumalai, J.H. Grabber, C.L. Davidson, X. Pan, J. Ralph, Hydroxycinnamate conjugates as potential monolignol replacements: in vitro lignification and cell wall studies with rosmarinic acid, ChemSusChem 5 (2012) 676-686.

[21] N. Yan, C. Zhao, P.J. Dyson, C. Wang, L. Liu, Y. Kou, Selective degradation of wood lignin over noble-metal catalysts in a two-step process, ChemSusChem 1 (2008) 626-629.

[22] R. Ma, Y. Xu, X. Zhang, Catalytic oxidation of biorefinery lignin to value-added chemicals to support sustainable biofuel production, ChemSusChem 8 (2015) 24-51.

[23] M. Dawange, M.V. Galkin, J.S.M. Samec, Selective aerobic benzylic alcohol oxidation of lignin model compounds: route to aryl ketones, ChemCatChem 7 (2015) 401-404

[24] S. Son, F.D. Toste, Non-oxidative vanadium-catalyzed CO bond cleavage: application to degradation of lignin model compounds, Angew. Chem. 122 (2010) 3879-3882.

[25] A. Rahimi, A. Ulbrich, J.J. Coon, S.S. Stahl, Formic-acid-induced depolymerization of oxidized lignin to aromatics, Nature 515 (2014) 249-252. This article demonstrated that the oxidation of the $\alpha$-hydroxy group in lignin could promote the subsequent cleavage of $\beta-0-4$ linkages by formic acid, resulting in a yield of low-molecular-weight fraction compounds over $60 \mathrm{wt} \%$.

[26] J.S. Luterbacher, A. Azarpira, A.H. Motagamwala, F. Lu, J. Ralph, J.A. Dumesic, Lignin monomer production integrated into the $\gamma$-valerolactone sugar platform, Energy Environ. Sci. 8 (2015) 2657-2663.

[27] L. Shuai, Y.M. Questell-Santiago, J.S. Luterbacher, A mild biomass pretreatment using $\gamma$-valerolactone for concentrated sugar production, Green Chem. 18 (2016) 937-943. This article compared various solvents for extracting lignin at mild pretreatment conditions, and found that $\gamma$-valerolactone (GVL) is superior to other solvents such as tetrohydrofuan (THF) and ethanol, for lignin extraction in acidic conditions.

[28] C. Xu, R.A.D. Arancon, J. Labidi, R. Luque, Lignin depolymerisation strategies: towards valuable chemicals and fuels, Chem. Soc. Rev. 43 (2014) 7485-7500.

[29] K. Sarkanen, C. Schuerch, Lignin structure. XI. A quantitative study of the alcoholysis of lignin, J. Am. Chem. Soc. 79 (1957) 4203-4209. 